\title{
Nota
}

\section{AVALIAÇÃO DO POTENCIAL EROSIVO DAS CHUVAS EM URUSSANGA, SC, NO PERÍODO DE 1980 A $2012^{(1)}$}

\author{
Morgana Levati Valvassori ${ }^{(2)} \&$ Álvaro José Back ${ }^{(3)}$
}

\begin{abstract}
RESUMO
O conhecimento do potencial erosivo das chuvas e a sua distribuição ao longo do ano contribuem para o planejamento de práticas de manejo e a conservação do solo, que visam a redução da erosão hídrica, diminuindo as perdas de solo e aumentando a produção agrícola. Este trabalho teve como objetivo caracterizar as chuvas da região de Urussanga, SC, com relação ao potencial erosivo, determinando os Índices de Erosividade mensais e anuais $\left(\mathrm{EI}_{30}\right)$ e estabelecendo assim o fator "R" para utilização na Equação Universal de Perdas de Solo, período de retorno e probabilidade de ocorrência das chuvas erosivas, a partir dos dados de chuva de diagramas diários do pluviógrafo da Estação Meteorológica de Urussanga, de outubro de 1980 a março de 2012. As chuvas foram digitalizadas em segmentos com intensidade constante. Foi elaborado um programa computacional para a leitura dos dados digitalizados, identificação das chuvas erosivas e realização dos cálculos de erosividade. A precipitação pluvial média anual foi de $1.781,8 \mathrm{~mm}$, dos quais $1.502,6 \mathrm{~mm}$ foram

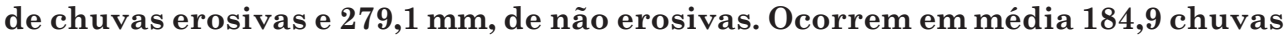
por ano, sendo $77,7 \%$ não erosivas e $22,3 \%$, erosivas. $O$ valor médio anual do índice $\mathrm{EI}_{30}$ é $5.665,10 \mathrm{MJ} \mathrm{mm} \mathrm{ha-1} \mathrm{h}^{-1}$, classificando as chuvas com erosividade média a forte. A época do ano com maior erosividade é de dezembro a março. $O$ fator " $R$ " da USLE, para regiões do entorno com características semelhantes de Urussanga, pode ser estimado com dados de pluviometria utilizando-se a equação linear ajustada.
\end{abstract}

Termos de indexação: erosividade, solos, chuvas erosivas, perdas de solos.

(1) Extraído da Dissertação de Mestrado em Ciências Ambientais do primeiro autor. Recebido para publicação em 27 de setembro de 2013 e aprovado em 27 de março de 2014.

(2) Engenheira Ambiental, Instituto de Pesquisas Ambientais Tecnológicas - Universidade Estadual de Santa Catarina. Rod. Gov. Jorge Lacerda, km 4,5. Caixa Postal 3167. CEP 88806-000 Criciúma (SC). E-mail: morganalevati@unesc.net

(3) Pesquisador, Empresa de Pesquisa Agropecuária e Extensão Rural de Santa Catarina. Rod. SC 446, km 16. Caixa Postal 49. CEP 88840-000 Urussanga (SC). E-mail: ajb@epagri.sc.gov.br 


\title{
SUMMARY: ASSESSMENT OF THE EROSIVE POTENTIAL OF RAINFALL IN URUSSANGA, SANTA CATARINA, BRAZIL FROM 1980 TO 2012
}

\begin{abstract}
Knowledge of the erosive potential of rainfall and its distribution throughout the year contribute to planning management and soil conservation practices that aim to reduce water erosion, decreasing soil loss and increasing crop yields. The goal of this study is to characterize rainfall in the region of Urussanga, SC, Brazil, in relation to its erosive potential, determining monthly and annual Erosivity Indices $\left(E I_{30}\right)$, thus establishing the $R$ factor to use in the Universal Soil Loss Equation. In addition, the goal is to determine hydrological patterns, return period, and the probability of the occurrence of erosive rainfalls based on rainfall data from the daily pluviograph records from the Meteorological Station of Urussanga from October 1980 to March 2012. The rainfall amounts were converted into digital information in segments with constant intensity. In addition, a computer program was developed to read this data, identify the erosive rainfalls, calculate the erosivity, and classify the hydrological patterns of rainfalls. The average annual rainfall was around $1,781.8 \mathrm{~mm}$, of which $1,502.6 \mathrm{~mm}$ were erosive rainfall and $279.1 \mathrm{~mm}$ non-erosive rainfall. There were an average of 184.9 rainfalls per year, of which $77.7 \%$ were non-erosive and $22.3 \%$ were erosive. The annual average value of the El30 index is 5,665.10 MJ mm ha-1 h-1, thus classifying the rainfalls as being of medium to strong erosivity. The period of greatest erosivity is from December to March. The $R$ factor of the USLE for areas with similar characteristics neighboring Urussanga can be estimated from pluviometer data using the fitted linear equation.
\end{abstract}

Index terms: erosivity, soil, erosive rainfall, soil loss.

\section{INTRODUÇÃO}

A crescente demanda por alimentos e energia gera, como um dos efeitos, a ampliação e intensificação do uso do solo, que associados às práticas inadequadas de manejo e conservação inviabilizam inúmeros sistemas de produção agropecuária. Nesse contexto, a erosão do solo é considerada um dos grandes problemas ambientais da atualidade, ocorrendo em escala global e ocasionando prejuízos nas esferas socioeconômica e ambiental.

A erosão hídrica é a principal causa de degradação de solos agrícolas por causa da remoção de nutrientes da camada superficial, que ocorre pela desagregação e pelo arraste das partículas do solo, reduzindo sua capacidade produtiva em razão da perda da camada de solo melhor estruturada e com maior teor de matéria orgânica e nutrientes, além de carrear fertilizantes e pesticidas para os mananciais hídricos (Cassol, 1986; Nascimento \& Chaves, 1996; Evangelista et al., 2006; Machado et al., 2008; Cassol et al., 2008).

O conhecimento das relações entre os fatores que causam as perdas de solo e os que permitem reduzílas é de fundamental importância para planejar ações conservacionistas adequadas e econômicas e elaborar projetos de controle de erosão. O planejamento conservacionista contempla estudos que priorizam a utilização racional para fins agrícolas e a preservação dos recursos naturais, principalmente água e solo (Oliveira, 1999; Botelho, 1999; Evangelista et al., 2006).

Na previsão de perdas de solo, é amplamente utilizada por pesquisadores no Brasil a Equação
Universal de Perdas de Solo (USLE), proposta por Wischmeier \& Smith (1978). Pode ser aplicada em áreas utilizadas para agricultura, em áreas em curso de recuperação e proteção ambiental, conforme citam Magalhães Filho et al. (2012), e em bacias hidrográficas, como indicado por Arroio Junior et al. (2012). O Índice de Erosividade é um dos fatores que compõe a equação, o qual expressa a capacidade da chuva de causar erosão em uma área sem proteção (Carvalho, 2008; Carvalho et al., 2010). A variação desse índice auxilia na escolha da melhor época para estabelecer práticas de manejo e conservação do solo (Val et al., 1986).

Este trabalho objetivou determinar os índices de erosividade - $\mathrm{EI}_{30}$, mensais e anuais, definir a energia cinética das chuvas individuais, estimar o valor do Fator "R" para uso na Equação Universal de Perdas de Solo (USLE), avaliar a distribuição anual e mensal do índice de erosividade local e precisar a probabilidade de ocorrência e o período de retorno dos índices mensais e anuais de erosividade. Trabalhos semelhantes foram desenvolvidos em vários estados brasileiros; porém, em Santa Catarina, apesar de haver vários pluviógrafos com séries históricas de mais de 20 anos, poucos foram os trabalhos publicados.

\section{MATERIAL E MÉTODOS}

Foram utilizados os dados da Estação Meteorológica de Urussanga (latitude 28,31 $\mathrm{S}$, longitude de $49,19^{\circ} \mathrm{W}$ e altitude de $49 \mathrm{~m}$ ). O clima da região, de acordo com o sistema de classificação climática de Köppen, é classificado como mesotérmico 
úmido com chuvas normalmente bem distribuídas e verão quente (Cfa). Segundo Dufloth et al. (2005), a temperatura do mês mais frio está na faixa de 13 a $15^{\circ} \mathrm{C}$, a da média normal varia de 17,0 a $19,3^{\circ} \mathrm{C}$, a da média normal das máximas varia de 23,4 a $25,9^{\circ} \mathrm{C}$ e das mínimas de 12,0 a $15,1^{\circ} \mathrm{C}$. A precipitação pluvial total normal anual pode variar de 1.220 a $1.660 \mathrm{~mm}$, com o total anual de dias de chuva entre 102 e 150.

No município de Urussanga, localizado no sul de Santa Catarina, predominam solos classificados nas ordens (Embrapa, 1992) Argissolos (65 \%) e Cambissolos (31\%), que, em razão do relevo variando de ondulado a forte ondulado, apresentam restrições de uso por causa da suscetibilidade à erosão (Dufloth et al., 2005). As principais culturas agrícolas em relação à área plantada são o fumo, milho e feijão, destacando-se ainda a fruticultura com cultivo de banana, pêssego e uva. No cultivo do fumo, adota-se o cultivo mínimo, enquanto o plantio direto é usado em aproximadamente 30 e $70 \%$ das áreas de cultivo do milho e feijão, respectivamente.

O trabalho foi desenvolvido a partir dos dados de chuva de diagramas do período de outubro/1980 a março/2012, seguindo a recomendação de Carvalho et al. (2005) de estudar séries históricas de no mínimo 22 anos. O modelo de pluviógrafo utilizado em Urussanga é do tipo Hellman Fuess, que fornece pluviogramas diários com precisão para chuvas com durações iguais ou superiores a $5 \mathrm{~min}$.

Os dados dos pluviogramas diários, que registram as chuvas em mm no eixo vertical e o tempo no eixo horizontal, com subdivisões em intervalos de $10 \mathrm{~min}$ em um período de $24 \mathrm{~h}$, foram digitalizados com o programa Gedac (Pedrollo, 1997). As chuvas foram digitalizadas em segmentos com intensidade constante. Foi elaborado um programa de computador em linguagem Delphi ${ }^{\circledR}$ para a leitura dos dados digitalizados e a realização dos cálculos.

Nesse programa constam os seguintes procedimentos:

1) Identificação da chuva individual: adotando os critérios sugeridos por Wischmeier \& Smith (1958), descritos em Cabeda (1976), em que foi considerada chuva individual aquela separada da anterior e da posterior, por um período mínimo de $6 \mathrm{~h}$ sem chuva ou com menos de $1 \mathrm{~mm}$;

2) Identificação da chuva erosiva: foram consideradas chuvas erosivas aquelas com quantidade igual ou superior a $10 \mathrm{~mm}$ ou igual ou superior a $6 \mathrm{~mm}$, em um período máximo de $15 \mathrm{~min}$;

3) Cálculo da energia cinética unitária: a energia cinética unitária de cada segmento uniforme de chuva foi obtida pela expressão proposta por Wischmeier \& Smith (1978) em unidades do Sistema Internacional:

$$
\mathrm{EC}=0,119+0,0873 \log \mathrm{i}
$$

em que EC é a energia cinética unitária $\left(\mathrm{MJ} \mathrm{ha}^{-1} \mathrm{~mm}^{-1}\right)$; e i, a intensidade da chuva dada $\mathrm{em} \mathrm{mm} \mathrm{h}^{-1}$ no segmento considerado;
4) Cálculo da energia cinética do segmento expressa em MJ ha-1, multiplicando a EC pela quantidade de chuva no respectivo segmento uniforme, isto é:

$$
\mathrm{Ecs}=\mathrm{EC} \mathrm{h}
$$

em que Ecs é a energia cinética do segmento (MJ ha-1); e h, a altura pluviométrica do segmento $(\mathrm{mm})$;

5) Cálculo da energia cinética total da chuva, somando-se a energia cinética de cada segmento uniforme, isto é:

$$
\mathrm{EC}_{\mathrm{t}}=\Sigma \mathrm{Ecs}
$$

6) Cálculo da intensidade máxima da chuva em um período de $30 \mathrm{~min}\left(\mathrm{I}_{30}\right)$;

7) Determinação do índice $\mathrm{EI}_{30}$, que representa a erosividade de cada chuva individual e erosiva por meio da seguinte expressão, conforme Cassol et al. (2007):

$$
\mathrm{EI}_{30}=\mathrm{EC}_{\mathrm{t}} \mathrm{I}_{30}
$$

em que $\mathrm{EI}_{30}$ é o índice de erosividade da chuva erosiva individual ( $\left.\mathrm{MJ} \mathrm{mm} \mathrm{ha}^{-1} \mathrm{~h}^{-1}\right) ; \mathrm{EC}_{\mathrm{t}}$, a energia cinética total da chuva ( $\left.\mathrm{MJ} \mathrm{ha}^{-1}\right)$; e $\mathrm{I}_{30}$, a intensidade máxima média de precipitação em $30 \mathrm{~min}\left(\mathrm{~mm} \mathrm{~h}^{-1}\right)$; e

8) Obtenção das somas mensais e anuais dos índices $\mathrm{EI}_{30}$, determinados para cada chuva individual e erosiva.

A partir da média da erosividade anual das chuvas no período analisado, obtém-se o Fator R da Equação Universal de Perda de Solo para aplicação em Urussanga e na região do entorno com características climáticas semelhantes.

Com base nos valores da intensidade máxima em $30 \min \left(\mathrm{I}_{30}\right)$ da chuva máxima erosiva e do índice de erosividade anual de chuva $\left(\mathrm{EI}_{30}\right)$, foram estimados o período de retorno de $2,5,10,20,25,50$ e 100 anos. Para determinação do período de retorno, foi utilizada a distribuição de Gumbel-Chow, e a aderência dos dados à distribuição foi avaliada com o teste de Kolmogorov-Smirnov a $5 \%$, conforme método descrito em Kite (1977).

Pela distribuição de Gumbel-Chow, o evento máximo com determinado período de retorno pode ser estimado como:

$$
X_{T}=\bar{x}+\left(Y-Y_{n}\right) \frac{S}{S_{n}}
$$

em que $\mathrm{X}_{\mathrm{T}}$ - evento máximo com período de retorno $\mathrm{T}$ anos, $\mathrm{mm} ; \overline{\mathrm{x}}$ - média da série de máximas anuais, $\mathrm{mm} ; \mathrm{S}$ - desvio padrão da série de máximas anuais, $\mathrm{mm} ; \mathrm{Y}_{\mathrm{n}}$ - média da variável reduzida; $\mathrm{S}_{\mathrm{n}}$ - desviopadrão da variável reduzida; e Y - variável reduzida calculada por:

$$
Y=-\ln \left\{-\ln \left(1-\frac{1}{T}\right)\right\}
$$

em que T é o período de retorno (anos).

Com os valores do índice de erosividade das chuvas e as chuvas mensal e anual, foram estabelecidas as 
relações linear e potencial entre a erosividade das chuvas calculada pelo Índice $\mathrm{EI}_{30}$ e o coeficiente de chuvas, conforme proposto por Lombardi Neto (1977),pelas seguintes expressões:

$$
\begin{gathered}
\mathrm{EI}_{30}=\mathrm{a}+\mathrm{bRc} \\
\mathrm{EI}_{30}=\mathrm{aRc}^{\mathrm{b}}
\end{gathered}
$$

em que $\mathrm{EI}_{30}$ é o índice de erosividade das chuvas $\left(\mathrm{MJ} \mathrm{mm} \mathrm{ha-1} \mathrm{h}^{-1}\right)$; a e b são os coeficientes de ajuste; $\mathrm{e}$ Rc é o coeficiente da chuva, em $\mathrm{mm}$, dado pela seguinte relação:

$$
\mathrm{Rc}=\frac{(\mathrm{Pm})^{2}}{\mathrm{~Pa}}
$$

em que Pm é a precipitação pluvial média mensal, em $\mathrm{mm} ; \mathrm{e} \mathrm{Pa}$, a precipitação pluvial média anual, em $\mathrm{mm}$.

\section{RESULTADOS E DISCUSSÃO}

No período de 1980 a 2012, a média anual de precipitação pluvial em Urussanga, SC, foi de $1.781,7 \mathrm{~mm}$, com médias mensais variando entre 94,6 e 222,2 mm (Quadro 1). Desse total, a média anual de chuvas erosivas foi de $1.502,6 \mathrm{~mm}^{-1} \mathrm{ano}^{-1}(84,3 \%)$ e a das não erosivas, $279,1 \mathrm{~mm}^{2} \mathrm{ano}^{-1}(15,7 \%)$. Em relação às médias mensais, os meses de janeiro, fevereiro, março e dezembro corresponderam a $42,8 \%$ do total de chuvas erosivas e representaram a maior pluviosidade média, respectivamente, com 222,2; 216,$3 ; 161,9$; e $171,6 \mathrm{~mm}$ de chuva. Os meses com menor pluviosidade média mensal foram junho (94,6 $\mathrm{mm}$ ) e agosto (115,1 $\mathrm{mm}$ ).

No quadro 1, são apresentadas as médias mensais dos números de chuvas não erosivas e erosivas no período estudado, obtendo-se a média anual de 184,9, sendo $77,7 \%$ não erosivas e $22,3 \%$, erosivas. No mês de janeiro ocorreu o maior número de chuvas erosivas.

Os valores mensais e anuais de erosividade, calculados conforme a equação da energia cinética proposta por Wischmeier \& Smith (1978), são apresentados no quadro 2 . Na série de dados analisada, foi encontrado o valor médio anual do índice $\mathrm{EI}_{30}$ igual a $5.665 \mathrm{MJ} \mathrm{mm} \mathrm{ha}^{-1} \mathrm{~h}^{-1}$ com desvio-padrão de $1.974 \mathrm{MJ} m \mathrm{ha}^{-1} \mathrm{~h}^{-1}$. Conforme a classificação desenvolvida por Silva et al. (2007), as chuvas em Urussanga, SC, são de erosividade média a forte.

$\mathrm{O}$ valor médio anual de $5.665 \mathrm{MJ} \mathrm{mm} \mathrm{ha}^{-1} \mathrm{~h}^{-1}$ representa o Fator "R" da Equação Universal de Perdas de Solo para uso local, podendo ser utilizado para os demais municípios que possuem características climáticas semelhantes. Os maiores valores de erosividade foram registrados nos meses de fevereiro de 1995 e janeiro de 2011, sendo respectivamente de 4.334 e $4.067 \mathrm{MJ} \mathrm{mm} \mathrm{ha}^{-1} \mathrm{~h}^{-1}$; já os menores valores, em novembro de 1989 e maio de 1985, com respectivamente 4 e $6 \mathrm{MJ} \mathrm{mm} \mathrm{ha}^{-1} \mathrm{~h}^{-1}$.

O maior índice de erosividade anual foi obtido em 1995 , no valor de $12.091 \mathrm{MJ} \mathrm{mm} \mathrm{ha}^{-1} \mathrm{~h}^{-1}$, sendo o valor mínimo de $2.847 \mathrm{MJ} \mathrm{mm} \mathrm{ha}^{-1} \mathrm{~h}^{-1}$ registrado em 1989. Valores de $\mathrm{EI}_{30}$ foram calculados para diferentes cidades brasileiras. Como exemplos, citam-se: Cassol et al. (2008), para São Borja, RS (9.751 MJ mm ha-1 $\mathrm{h}^{-1}$ ), considerado um dos índices mais altos do país, sendo utilizada a série histórica de 47 anos; Cassol et al. (2007), para Ijuí, RS (1.667 $\mathrm{MJ} \mathrm{mm} \mathrm{ha}^{-1} \mathrm{~h}^{-1}$ ), considerado um dos menores índices de erosividade registrados no país, empregando a série histórica de 30 anos; Mazurana et al. (2009), para Santa Rosa, RS (11.271 MJ mm ha-1 $\mathrm{h}^{-1}$ ), com a série histórica de 28 anos; Dias \& Silva (2003), para Fortaleza, CE (6.774 MJ mm ha $\left.{ }^{-1} \mathrm{~h}^{-1}\right)$, usando a série histórica de

\begin{tabular}{|c|c|c|c|c|c|c|c|c|c|c|c|c|}
\hline \multirow{3}{*}{ Mês } & \multicolumn{6}{|c|}{ Altura de chuva } & \multicolumn{6}{|c|}{ Número de chuva } \\
\hline & \multirow{2}{*}{$\frac{\text { Não }}{\mathrm{mm}}$} & \multirow{2}{*}{$\begin{array}{r}\text { erosiva } \\
\%\end{array}$} & \multicolumn{2}{|c|}{ Erosiva } & \multicolumn{2}{|c|}{ Total } & \multicolumn{2}{|c|}{ Não erosiva } & \multicolumn{2}{|c|}{ Erosiva } & \multicolumn{2}{|c|}{ Total } \\
\hline & & & $\mathrm{mm}$ & $\%$ & $\mathrm{~mm}$ & $\%$ & $\mathrm{n}^{\mathrm{o}}$ & $\%$ & $\mathrm{n}^{\mathrm{o}}$ & $\%$ & $\mathrm{n}^{\mathrm{o}}$ & $\%$ \\
\hline Jan. & 35,0 & 1,97 & 187,2 & 10,50 & 222,2 & 35,0 & 15,9 & 8,6 & 5,3 & 2,9 & 21,2 & 11,5 \\
\hline Fev. & 36,9 & 2,07 & 179,4 & 10,06 & 216,3 & 36,9 & 16,1 & 8,7 & 5,0 & 2,7 & 21,2 & 11,4 \\
\hline Mar. & 28,0 & 1,57 & 133,9 & 7,51 & 161,9 & 28,0 & 14,0 & 7,6 & 4,0 & 2,2 & 18,0 & 9,7 \\
\hline Abr. & 23,0 & 1,29 & 96,5 & 5,41 & 119,5 & 23,0 & 12,9 & 7,0 & 2,7 & 1,4 & 15,6 & 8,4 \\
\hline Mai. & 19,4 & 1,09 & 110,6 & 6,21 & 130,0 & 19,4 & 9,9 & 5,3 & 2,6 & 1,4 & 12,5 & 6,7 \\
\hline Jun. & 16,4 & 0,92 & 78,2 & 4,38 & 94,6 & 16,4 & 10,4 & 5,6 & 2,3 & 1,3 & 12,8 & 6,9 \\
\hline Jul. & 20,6 & 1,15 & 104,4 & 5,86 & 125,0 & 20,6 & 10,6 & 5,7 & 2,9 & 1,5 & 13,5 & 7,3 \\
\hline Ago. & 20,7 & 1,16 & 94,4 & 5,29 & 115,1 & 20,7 & 9,5 & 5,1 & 2,7 & 1,5 & 12,2 & 6,6 \\
\hline Set. & 19,8 & 1,11 & 120,2 & 6,74 & 140,0 & 19,8 & 12,2 & 6,6 & 3,7 & 2,0 & 15,9 & 8,6 \\
\hline Out. & 27,7 & 1,55 & 129,7 & 7,28 & 157,4 & 27,7 & 14,1 & 7,6 & 3,8 & 2,0 & 17,8 & 9,6 \\
\hline Nov. & 26,1 & 1,46 & 121,5 & 6,82 & 147,7 & 26,1 & 13,5 & 7,3 & 3,9 & 2,1 & 17,4 & 9,4 \\
\hline Dez. & 28,4 & 1,60 & 143,2 & 8,03 & 171,6 & 28,4 & 13,6 & 7,4 & 3,9 & 2,1 & 17,5 & 9,4 \\
\hline Ano & 279,1 & 15,65 & 1502,6 & 84,28 & 1781,7 & 279,1 & 143,6 & 77,7 & 41,3 & 22,3 & 184,9 & 100,0 \\
\hline
\end{tabular}
18 anos; Evangelista et al. (2006), para Lavras, MG

Quadro 1. Médias mensais de altura e número de chuvas não erosivas, erosivas e total em Urussunga, SC 
Quadro 2. Valores mensais e anuais do índice de erosividade $\mathrm{EI}_{30}$, com dados pluviográficos de Urussanga, SC, com os respectivos parâmetros estatísticos

\begin{tabular}{|c|c|c|c|c|c|c|c|c|c|c|c|c|c|}
\hline \multirow{2}{*}{ Ano } & \multicolumn{13}{|c|}{ Índice de erosividade $\left(\mathrm{EI}_{30}\right)^{(1)}$} \\
\hline & Jan & Fev & Mar & Abr & Maio & Jun & Jul & Ago & Set & Out & Nov & Dez & Anual \\
\hline & & & & & & $-\mathrm{N}$ & $\mathrm{nm}$ ha & $a^{-1}-$ & & & & & \\
\hline 1980 & - & - & - & - & - & - & - & - & - & 182 & 53 & 960 & \\
\hline 1981 & 441 & 746 & 417 & 640 & 577 & 430 & 333 & 33 & 243 & 82 & 518 & 127 & 4587 \\
\hline 1982 & 232 & 908 & 1680 & 448 & 33 & 260 & 182 & 7 & 14 & 311 & 202 & 414 & 4692 \\
\hline 1983 & 1050 & 317 & 612 & 316 & 61 & 220 & 231 & 436 & 23 & 112 & 866 & 2510 & 6752 \\
\hline 1985 & 122 & 3864 & 609 & 46 & 6 & 327 & 59 & 322 & 39 & 428 & 437 & 1076 & 7336 \\
\hline 1986 & 174 & 595 & 297 & 481 & 194 & 12 & 90 & 93 & 145 & 770 & 891 & 669 & 4409 \\
\hline 1987 & 726 & 1149 & 274 & 683 & 526 & 180 & 330 & 909 & 88 & 1052 & 591 & 263 & 6770 \\
\hline 1988 & 1087 & 132 & 604 & 662 & 43 & 216 & 21 & 76 & 641 & 461 & 872 & 577 & 5390 \\
\hline 1989 & 662 & 670 & 208 & 107 & 135 & 49 & 73 & 130 & 559 & 84 & 4 & 166 & 2847 \\
\hline 1990 & 190 & 1111 & 68 & 579 & 255 & 56 & 63 & 143 & 286 & 830 & 581 & 2725 & 6887 \\
\hline 1991 & 243 & 764 & 248 & 632 & 8 & 59 & 38 & 127 & 58 & 134 & 400 & 618 & 3327 \\
\hline 1992 & 442 & 706 & 877 & 21 & 1089 & 38 & 249 & 54 & 163 & 25 & 467 & 250 & 4381 \\
\hline 1993 & 1914 & 576 & 515 & 239 & 23 & 8 & 297 & 9 & 452 & 193 & 257 & 1398 & 5881 \\
\hline 1994 & 1206 & 1411 & 891 & 110 & 1421 & 25 & 109 & 31 & 613 & 273 & 190 & 1365 & 7644 \\
\hline 1995 & 3333 & 4334 & 390 & 70 & 82 & 257 & 187 & 59 & 118 & 203 & 190 & 2870 & 12091 \\
\hline 1996 & 2631 & 1103 & 290 & 633 & 82 & 213 & 58 & 437 & 163 & 174 & 117 & 725 & 6627 \\
\hline 1997 & 1860 & 1584 & 340 & 487 & 78 & 202 & 320 & 97 & 62 & 405 & 621 & 61 & 6116 \\
\hline 1998 & 1227 & 1705 & 1068 & 129 & 32 & 207 & 104 & 241 & 138 & 405 & 156 & 411 & 5822 \\
\hline 1999 & 565 & 982 & 1925 & 233 & 18 & 54 & 105 & 33 & 32 & 134 & 331 & 255 & 4667 \\
\hline 2000 & 642 & 114 & 431 & 196 & 24 & 180 & 38 & 77 & 263 & 878 & 306 & 51 & 3200 \\
\hline 2001 & 1314 & 840 & 208 & 207 & 124 & 71 & 339 & 44 & 152 & 508 & 192 & 63 & 4062 \\
\hline 2002 & 355 & 284 & 1340 & 55 & 193 & 163 & 55 & 59 & 96 & 289 & 507 & 8 & 3405 \\
\hline 2003 & 1245 & 1203 & 942 & 232 & 90 & 57 & 52 & 79 & 186 & 139 & 67 & 658 & 4949 \\
\hline 2004 & 507 & 136 & 254 & 712 & 759 & 61 & 335 & 17 & 767 & 86 & 378 & 256 & 4266 \\
\hline 2005 & 195 & 303 & 503 & 68 & 87 & 15 & 117 & 945 & 503 & 777 & 205 & 76 & 3793 \\
\hline 2006 & 1569 & 510 & 241 & 2318 & 93 & 15 & 120 & 336 & 369 & 38 & 664 & 46 & 6318 \\
\hline 2007 & 410 & 760 & 1539 & 651 & 274 & 6 & 218 & 124 & 171 & 75 & 248 & 2247 & 6723 \\
\hline 2008 & 203 & 1211 & 585 & 135 & 349 & 42 & 308 & 143 & 166 & 782 & 384 & 430 & 4738 \\
\hline 2009 & 2371 & 1892 & 2169 & 408 & 216 & 71 & 57 & 247 & 1018 & 45 & 546 & 281 & 9322 \\
\hline 2010 & 1810 & 457 & 709 & 255 & 822 & 62 & 56 & 105 & 32 & 52 & 827 & 7 & 5192 \\
\hline 2011 & 4067 & 1115 & 248 & 86 & 121 & 115 & 252 & 644 & 209 & 61 & 676 & 170 & 7762 \\
\hline 2012 & 248 & 1226 & 167 & - & - & - & - & - & - & - & - & - & \\
\hline Média & 1066 & 1055 & 666 & 395 & 260 & 122 & 160 & 202 & 259 & 322 & 411 & 701 & 5665 \\
\hline Desvio & 989 & 936 & 546 & 432 & 348 & 109 & 112 & 248 & 250 & 297 & 256 & 832 & 1974 \\
\hline Máximo & 4067 & 4334 & 2169 & 2318 & 1421 & 430 & 339 & 945 & 1018 & 1052 & 891 & 2870 & 12091 \\
\hline Mínimo & 122 & 114 & 68 & 21 & 6 & 6 & 21 & 7 & 14 & 25 & 4 & 7 & 2847 \\
\hline
\end{tabular}

(1) Calculado conforme a equação da energia cinética proposta por Wischmeier \& Smith (1978).

(5.403 MJ mm ha $\left.{ }^{-1} \mathrm{~h}^{-1}\right)$, utilizando os dados de série pluviográfica de 15 anos; Bertol $(1993 ; 1994)$, para os municípios de Lages (5.694 MJ mm ha-1 $\mathrm{h}^{-1}$ ) e Campos Novos (6.329 MJ mm ha $\left.{ }^{-1} \mathrm{~h}^{-1}\right)$, ambos em Santa Catarina, com a série histórica de nove anos; Carvalho et al. (2005), para os municípios de Seropédica (5.472 MJ mm ha-1 $\mathrm{h}^{-1}$ ) e Nova Friburgo (5.430 MJ mm ha-1 $\mathrm{h}^{-1}$ ), ambos no Rio de Janeiro, utilizando a série de dados de seis anos.

A distribuição relativa do índice de erosividade, ou seja, a média mensal acumulada a cada mês é apresentada na figura 1 . Os meses de maior erosividade são dezembro, janeiro, fevereiro e março. Ressalta-se que quanto maior for a inclinação da curva para determinado período, maior é o risco de ocorrência de erosão no solo, demandando maior atenção com aplicação de práticas conservacionistas nesse período.

De maneira geral, os meses de verão têm valores maiores de erosividade, enquanto no inverno encontram-se os menores. As principais culturas típicas de verão verificadas em Urussanga são milho, mandioca, feijão e fumo, com a semeadura ou o plantio concentrado de setembro a novembro. 
No quadro 3, evidenciam-se os resultados do período de estudo para as intensidades máximas de chuvas ocorridas em 30 min $\left(\mathrm{I}_{30}\right)$, a chuva erosiva máxima anual e o índice de erosividade anual. Na figura 2 , está ilustrada a representação do teste de aderência dessas séries à distribuição de Gumbel-Chow ajustada. Kite (1977) e Wilks (2006) discutiram diferentes testes de aderência e apresentaram indicações que o teste de Kolmogorov-Smirnov é superior ao do Qui-Quadrado e outros testes não paramétricos. A estatística desse teste é a diferença máxima (Dmáx) entre a distribuição acumulativa observada e a estimada, conforme a distribuição testada. Na série de intensidade máxima em 30 min, obteve-se a melhor aderência, com valor de Dmáx $=0,062$ (Figura 2a). Para a série de chuvas erosivas máximas anuais (Figura 2b), observaram-se maiores diferenças (Dmáx $=0,167$ ); no entanto, inferior ao valor crítico do teste de KolmogorovSmirnov a $5 \%$ (Dcrítico $=0,234)$. Para o índice de erosividade anual (Figura 2c), o valor de Dmáx foi de 0,068 , indicando adequada aderência à distribuição ajustada.

O maior valor encontrado de intensidade máxima em $30 \mathrm{~min}$ foi em fevereiro de $1995\left(123,2 \mathrm{~mm} \mathrm{~h}^{-1}\right)$, quando também foi verificado o maior Índice de Erosividade (Quadro 3). A intensidade média da chuva máxima com duração de 30 min é de 63,9 $\mathrm{mm} \mathrm{h}^{-1}$. Esse resultado está de acordo com os valores observados por Back et al. (2011), os quais ajustaram as equações de chuvas intensas para 13 estações com dados de pluviógrafos de Santa Catarina. Os autores encontraram valores médios de chuva máxima com duração de $30 \mathrm{~min}$, variando de 16,7 mm, em Itajaí, a 32,2 mm, em Florianópolis, o

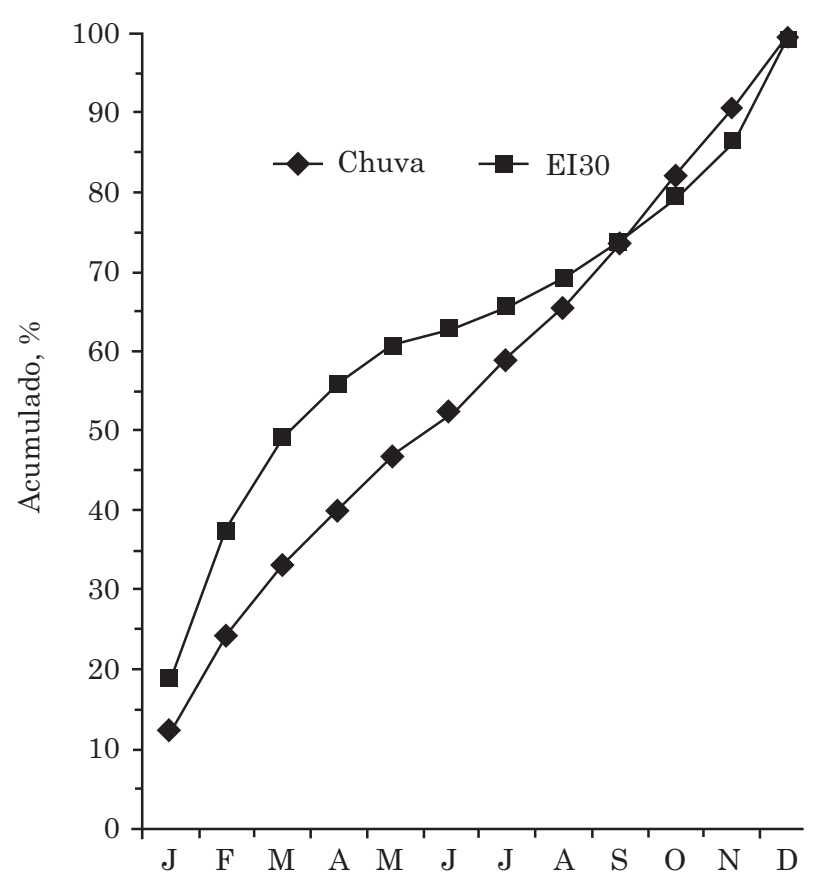

Figura 1. Distribuição acumulada da chuva e do índice de erosividade ( $\left.\mathrm{EI}_{30}\right)$ em Urussanga, $\mathrm{SC}$. que corresponde a intensidades de 33,4 a $64,4 \mathrm{~mm} \mathrm{~h}^{-1}$, respectivamente.

O maior Índice de Erosividade encontrado ocorreu em fevereiro de 1995 (3.337,23 MJ mm ha-1 $\left.\mathrm{h}^{-1}\right)$ (Quadro 3). Em janeiro de 1985, obteve-se o segundo maior resultado (3.201,84 $\left.\mathrm{MJ} \mathrm{mm} \mathrm{ha}^{-1} \mathrm{~h}^{-1}\right)$. O menor resultado foi registrado em outubro de 2001 $\left(349,47 \mathrm{MJ} \mathrm{mm} \mathrm{ha-1} \mathrm{h}^{-1}\right)$. Com relação à época de ocorrência dos eventos extremos, a maioria ocorreu nos meses de janeiro a março. Somente em três anos os eventos máximos anuais não ocorreram entre os meses de outubro a março. Essa constatação é importante do ponto de vista de recomendações de práticas de manejo do solo e controle de erosão, indicando as épocas do ano em que se deve manter o solo com cobertura vegetal.

Com relação ao Índice de Erosividade Anual, os valores variaram de $2.847,1 \mathrm{a} 12.091,32 \mathrm{MJ} \mathrm{mm} \mathrm{ha}^{-1} \mathrm{~h}^{-1}$,

Quadro 3. Intensidade máxima em $30 \mathrm{~min}\left(\mathrm{I}_{30}\right)$, chuva erosiva máxima anual e índice de erosividade anual $\left(\mathrm{EI}_{30}\right)$ observada em Urussanga, $\mathrm{SC}$

\begin{tabular}{rrrrrr}
\hline Ano & & $\mathbf{I}_{30}$ & & Chuva erosiva & EI $_{30}$ \\
\hline & Mês & mm h$^{-1}$ & Mês & - MJ mm & ha $^{1} \mathrm{~h}^{-1}-$ \\
1981 & 4 & 40,6 & 2 & 636,7 & $4.586,6$ \\
1982 & 3 & 62,2 & 3 & 668,7 & $4.691,9$ \\
1983 & 12 & 73,6 & 12 & 854,3 & $6.751,8$ \\
1985 & 12 & 77,2 & 1 & $3.201,8$ & $7.335,8$ \\
1986 & 12 & 51,2 & 11 & 711,3 & $4.409,4$ \\
1987 & 2 & 49,4 & 2 & 527,9 & $6.769,7$ \\
1988 & 11 & 62,2 & 11 & 872,2 & $5.390,1$ \\
1989 & 2 & 42,4 & 1 & 512,6 & $2.847,1$ \\
1990 & 12 & 73,8 & 12 & $2.270,3$ & $6.886,5$ \\
1991 & 4 & 51,8 & 2 & 458,8 & $3.327,4$ \\
1992 & 3 & 68,6 & 3 & 842,9 & $4.380,6$ \\
1993 & 1 & 74,6 & 1 & 834,5 & $5.881,0$ \\
1994 & 2 & 74,8 & 2 & 916,9 & $7.643,7$ \\
1995 & 2 & 123,2 & 2 & $3.337,2$ & $12.091,3$ \\
1996 & 1 & 56,0 & 1 & $1.377,9$ & $6.627,1$ \\
1997 & 2 & 64,0 & 1 & 933,0 & $6.116,4$ \\
1998 & 1 & 66,4 & 1 & 969,9 & $5.821,5$ \\
1999 & 2 & 44,6 & 2 & 571,9 & $4.667,0$ \\
2000 & 1 & 41,2 & 10 & 709,0 & $3.199,6$ \\
2001 & 10 & 33,8 & 10 & 349,4 & $4.061,7$ \\
2002 & 3 & 47,0 & 3 & 841,1 & $3.404,5$ \\
2003 & 3 & 88,0 & 3 & $1.215,9$ & $4.948,9$ \\
2004 & 4 & 41,2 & 5 & 519,1 & $4.265,7$ \\
2005 & 5 & 38,0 & 5 & 944,5 & $3.793,2$ \\
2006 & 4 & 96,8 & 4 & $2.302,3$ & $6.317,9$ \\
2007 & 12 & 96,0 & 12 & $1.797,6$ & $6.723,2$ \\
2008 & 2 & 59,0 & 2 & 697,9 & $4.737,6$ \\
2009 & 3 & 84,4 & 3 & $1.662,8$ & $9.321,6$ \\
2010 & 1 & 74,8 & 1 & $1.114,5$ & $5.191,9$ \\
2011 & 1 & 60,6 & 1 & $1.175,7$ & $7.762,2$ \\
\hline & & & & &
\end{tabular}




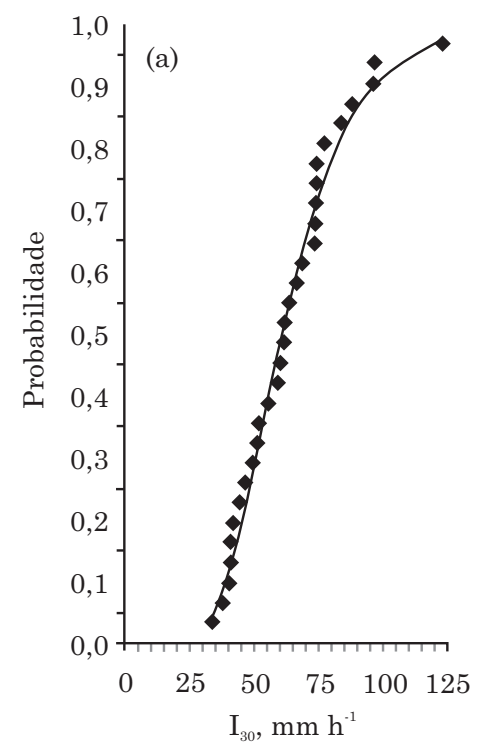

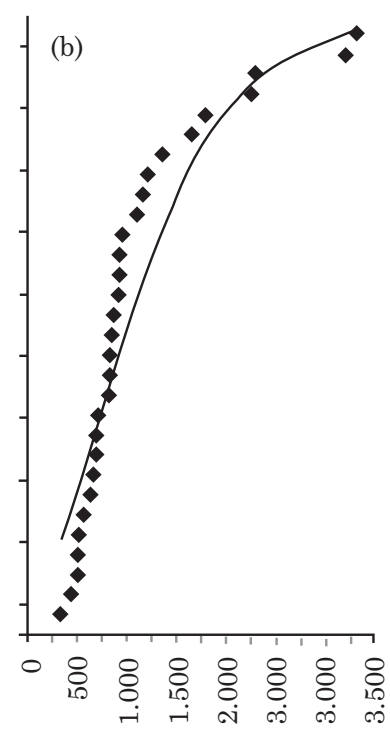

Chuva erosiva, MJ mm ha ${ }^{-1} \mathrm{~h}^{-1}$

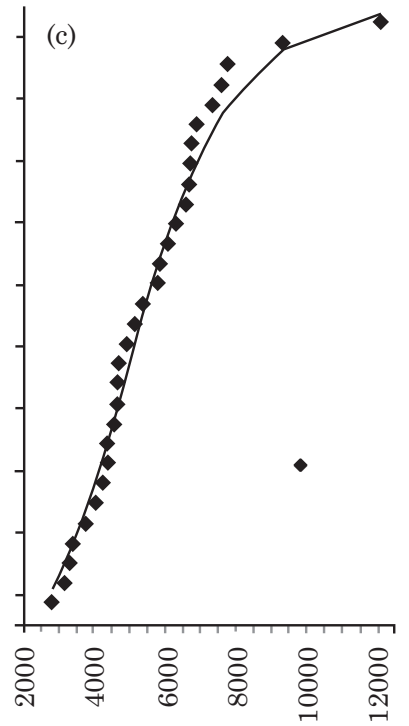

$\mathrm{EI}_{30}, \mathrm{MJ} \mathrm{mm} \mathrm{ha}^{-1} \mathrm{~h}^{-1}$

Figura 2. Estimativa da intensidade máxima em $30 \mathrm{~min}\left(\mathrm{I}_{30}\right)(\mathrm{a})$, da chuva erosiva (b) e índice de erosividade anual de chuvas (c) para Urussanga, SC. Os diamantes azuis ( $\bullet$ ) representam a frequência observada e a linha vermelha (-) representa a frequência esperada, segundo a distribuição de Gumbel.

Quadro 4. Intensidade máxima em 30 min $\left(I_{30}\right)$, chuva erosiva máxima anual e índice de erosividade anual $\left(\mathrm{EI}_{30}\right)$ estimados para diferentes períodos de retorno para Urussanga, $\mathrm{SC}$

\begin{tabular}{crcr}
\hline Período de retorno & \multicolumn{1}{c}{$\mathbf{I}_{\mathbf{3 0}}$} & Chuva erosiva & $\mathbf{E I}_{\mathbf{3 0}}$ \\
\hline ano & $\mathrm{mm} \mathrm{h}^{-1}$ & \multicolumn{2}{c}{$\mathrm{MJ} \mathrm{mm}^{-1} \mathrm{~h}^{-1}-$} \\
2 & 60,8 & $1.012,0$ & $5.363,9$ \\
5 & 81,7 & $1.784,3$ & $7.375,6$ \\
10 & 95,6 & $2.295,7$ & $8.707,5$ \\
15 & 103,4 & $2.584,2$ & $9.459,0$ \\
20 & 108,9 & $2.786,2$ & $9.985,1$ \\
25 & 113,1 & $2.941,8$ & $10.390,4$ \\
50 & 126,2 & $3.421,1$ & $11.638,9$ \\
100 & 139,1 & $3.896,9$ & $12.878,1$ \\
\hline
\end{tabular}

com média de 5.664,1 MJ mm ha-1 $\mathrm{h}^{-1}$. No quadro 4, apresentam-se os valores estimados para diferentes períodos de retorno. O Índice de Erosividade Anual com período de retorno de cinco anos pode ser estimado com 7.375,6 MJ mm ha ${ }^{-1} \mathrm{~h}^{-1}$. Assim, poderia ser incluído um fator de risco na USLE, adotando o índice de erosividade de chuvas com determinado nível de probabilidade de recorrência ou período de retorno, e não somente o valor médio.

$\mathrm{Na}$ figura 3, evidenciam-se as equações de regressão ajustadas entre o índice de erosividade médio mensal e o coeficiente de chuvas de Urussanga. Houve melhor ajuste $\left(\mathrm{R}^{2}=0,908\right)$ para o modelo linear, que se apresentou significativo $(p<0,01)$. Assim, o índice de erosividade médio mensal para Urussanga pode ser estimado pela equação:

$$
\mathrm{EI}_{30}=-127,05+45,10 \mathrm{Rc}
$$

em que $\mathrm{EI}_{30}$ é o índice de erosividade das chuvas (MJ mm ha ${ }^{-1} \mathrm{~h}^{-1}$ ); Rc é o coeficiente da chuva definido na equação 9 .

Vários trabalhos apresentaram que existe relação linear significativa entre o coeficiente de chuvas (Rc) e o índice de erosividade das chuvas $\left(\mathrm{EI}_{30}\right)$. Rufino et al. (1993) obtiveram relação linear para oito regiões do Paraná com coeficiente de determinação $\left(R^{2}\right)$ variando de 0,70 a 0,86 . Também Peñalva-Bazzano et al. (2007), analisando dados de chuva de Quarai, RS, concluíram que a relação linear foi significativa. Cassol et al. (2008), utilizando a série histórica de 47 anos de São Borja, RS, ajustaram a relação $\mathrm{EI}_{30}=99,646+63,874 \mathrm{Rc}$ com $\mathrm{R}^{2}=0,771$. Bertol (1993), com base em série de nove anos de dados de Lages, SC, ajustou a relação $\mathrm{EI}_{30}=6,93+0,01 \mathrm{Rc}$, obtendo $R^{2}=0,61$. No entanto, existem alguns trabalhos em que as regressões não foram significativas, como os de Bertol (1994), para Campos Novos, SC; Cassol et al. (2007), para Ijuí, RS; Martins et al. (2009), para Encruzilhadinha do Sul, RS; e Mazurana et al. (2009), para Santa Rosa, RS. Essa aparente discrepância nos resultados evidenciou a importância de realizar estudos com dados locais e ajustar o modelo para ser aplicado na região com clima semelhante.

Com a equação ajustada para Urussanga, SC, pôdese estimar o valor do índice de erosividade das chuvas para a região sul do Estado de Santa Catarina, onde existem dezenas de pluviômetros instalados (ANA, 2009); no entanto, um dos poucos pluviógrafos existentes é o da estação de Urussanga, cujos dados foram usados neste trabalho. 

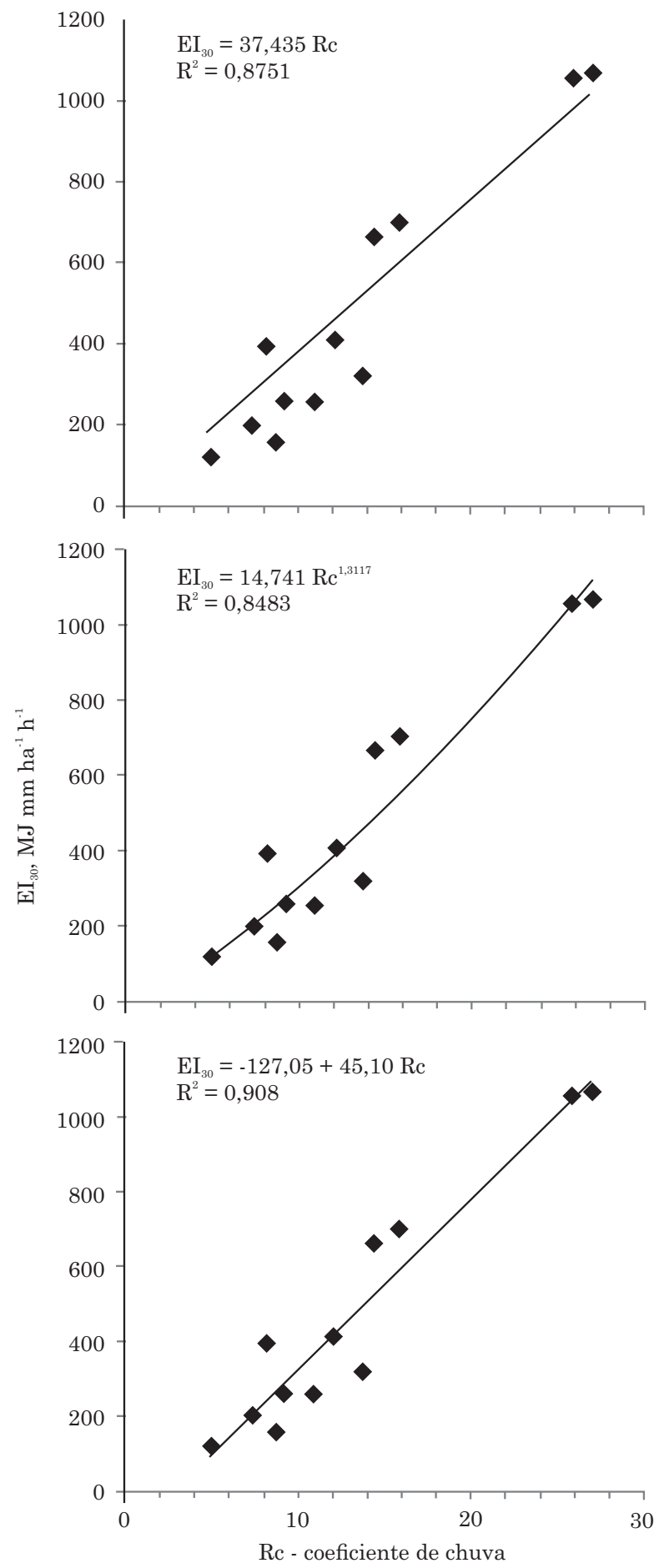

Figura 3. Curvas de ajuste entre o índice de erosividade $\left(\mathrm{EI}_{30}\right)$ médio mensal e o coeficiente de chuva (Rc) para Urussanga, SC.

\section{CONCLUSÕES}

1. No período de 1980 a 2012 , foram registrados $1.781,8 \mathrm{~mm}$ de precipitação pluvial média anual, dos quais $1.502,6 \mathrm{~mm}$ foram de chuvas erosivas $\mathrm{e}$ $279,1 \mathrm{~mm}$, de não erosivas.
2. Da média de 185 chuvas por ano, $77,7 \%$ foram de não erosivas e $22,3 \%$ de erosivas.

3. $\mathrm{O}$ valor médio anual do índice $\mathrm{EI}_{30}$ permitiu classificar as chuvas da região de Urussanga, SC, como de erosividade média a forte.

4. O maior Índice de Erosividade Anual obtido em 1995 foi de $12.091,3 \mathrm{MJ} \mathrm{mm} \mathrm{ha-1} \mathrm{h}^{-1}$, e o valor mínimo de $2.847,1 \mathrm{MJ} \mathrm{mm} \mathrm{ha}^{-1} \mathrm{~h}^{-1}$ foi registrado em 1989.

5. O Índice de Erosividade Anual com período de retorno de cinco anos pôde ser estimado em 7.375,6 MJ mm ha-1 $\mathrm{h}^{-1}$. Assim, poderia ser incluído um fator de risco na USLE, adotando o índice de erosividade de chuvas com determinado nível de probabilidade de recorrência ou período de retorno, e não somente o valor médio.

6. A época do ano com maior erosividade de chuvas foi o período de dezembro a março.

7. A época de maior ocorrência dos eventos extremos anuais de intensidade da chuva máxima em 30 min e chuva erosiva máxima anual foi o período de outubro a março.

8. O fator "R" da USLE, para regiões do entorno de Urussanga, SC, com características semelhantes, pôde ser estimado com dados de pluviometria utilizando-se a equação linear ajustada.

\section{LITERATURA CITADA}

AGÊNCIA NACIONAL DE ÁGUAS - ANA. Inventário das Estações Pluviométricas. Brasília, ANA/SGH, 2009. 332p.

ARROIO JUNIOR, P.P.; RODRIGUES, T.; KUWAJIMA, J.I. \& MAUAD, F.F. Avaliação espaço-temporal da perda de solo por erosão laminar na bacia hidrográfica do reservatório do Broa, municípios de Itirapina e Brotas SP. In: ENCONTRO NACIONAL DE ENGENHARIA DE SEDIMENTOS, 10., Foz do Iguaçu, 2012. Anais... Foz do Iguaçu, ABRH, 2012. CD-ROM

BACK, Á.J. Time distribution of heavy rainfall events in Urussanga, Santa Catarina State, Brazil. Acta. Sci. Agron., 3:583-588, 2011.

BERTOL, I. Índice de erosividade $\left(\mathrm{EI}_{30}\right)$ para Lages (SC) - $1^{\mathrm{a}}$ Aproximação. Pesq. Agropec. Bras., 28:515-521, 1993.

BERTOL, I. Avaliação da erosividade da chuva na localidade de Campos Novos (SC) no período de 1981-1990. Pesq. Agropec. Bras., 29:1453-1458, 1994.

BOTELHO, R.G.M. Planejamento ambiental em microbacia hidrográfica. In: GUERRA, A.J.T.; SILVA, A.S. \& BOTELHO, R.G.M., orgs. Erosão e conservação dos solos: Conceitos, temas e aplicações. Rio de Janeiro, Bertrand Brasil, 1999. p.70-300.

CABEDA, M.S.V. Computation of storm EI values. West Lafayette, Purdue University, 1976. 6p. 
CARVALHO, D.F.; MONTEBELLER, C.A.; FRANCO, E.M.; VALCARCEL, R. \& BERTOL, I. Padrões de precipitação e índices de erosividade para as chuvas de Seropédica e Nova Friburgo, RJ. R. Bras. Eng. Agríc. Amb., 9:7-14, 2005.

CARVALHO, N.O. Hidrossedimentologia prática. 2.ed. Rio de Janeiro, Interciência, 2008. 599p.

CARVALHO, D.F.; MACHADO, R.L.; EVANGELISTA, A.W.P.; KHOURY JUNIOR, J.K. \& DILVA, L.D.B. Distribuição, probabilidade de ocorrência e período de retorno dos índices de erosividade $\mathrm{EI}_{30}$ e $\mathrm{KE}>25$ em Seropédica - RJ. Eng. Agríc., 30:244-252, 2010.

CASSOL, E.A. Erosão do solo: Influência do uso agrícola, do manejo e preparo do solo. 2.ed. Porto Alegre, IPRNR, 1986. 40p.

CASSOL, E.A.; MARTINS, D.; ELTZ, F.L.F.; LIMA, V.S. \& BUENO, A.C. Erosividade e padrões hidrológicos das chuvas de Ijuí (RS) no período de 1963 a 1993. R. Bras. Agrometeorol., 15:220-231, 2007.

CASSOL, E.A.; ELTZ, F.L.F.; MARTINS, D.; LEMOS, A.M.; LIMA, V.D. \& BUENO, A.C. Erosividade, padrões hidrológicos, período de retorno e probabilidade de ocorrência das chuvas em São Borja, RS. R. Bras. Ci. Solo, 32:1239-1251, 2008.

DIAS, A.S. \& SILVA, J.R.C. A erosividade das chuvas em Fortaleza (CE). I - Distribuição, probabilidade de ocorrência e período de retorno - $1^{a}$ aproximação. R. Bras. Ci. Solo, 27:335-345, 2003.

DUFLOTH, J.H.; CORTINA, N.; VEIGA; M. \& MIOR, L.C. Estudos básicos regionais de Santa Catarina. Florianópolis, EPAGRI, 2005. CD-ROM

EMPRESA BRASILEIRA DE PESQUISA AGROPECUÁRIA EMBRAPA. Centro Nacional de Pesquisa de Solos. Sistema brasileiro de classificação de solos. Brasília, Sistema de Produção e Informação, 1992.

EVANGELISTA, A.W.P.; CARVALHO, L.G.; DANTAS, A.A.A. \& BERNARDINO, D.T. Potencial erosivo das chuvas em Lavras, MG: Distribuição, probabilidade de ocorrência e período de retorno. Irriga, 11:1-11, 2006.

KITE, G.W. Frequency and risk analyses in hydrology. Fort Collins, Water Resources Publications, 1977. 224p.

LOMBARDI-NETO, F. Rainfall erosivity - its distribution and relationship with soil loss at Campinas, Brazil. West Lafayette, Purdue University, 1977. 53p. (Doctoral Thesis)

MACHADO, R.L.; CARVALHO, D.F.; COSTA, J.R.; OLIVEIRA NETO, D.H. \& PINTO, M.F. Análise da erosividade das chuvas associada aos padrões de precipitação pluvial na região de Ribeirão das Lages (RJ). R. Bras. Ci. Solo, 32:2113-2123, 2008.
MAGALHÃES FILHO, F.J.C.; MAACHAR, A.F.; AYRES, F.M. \& SOBRINHO, T.A. Integrando SIG e USLE para mapeamento da perda de solo em área de proteção ambiental. In: ENCONTRO NACIONAL DE ENGENHARIA DE SEDIMENTOS, 10., Foz do Iguaçu, 2012. Anais... Foz do Iguaçu, ABRH, 2012. CD-ROM

MARTINS, D.; CASSOL, E.A.; ELTZ, F.L.F. \& BUENO, A.C. Erosividade e padrões hidrológicos das chuvas de Hulha Negra, Rio Grande do Sul, Brasil, com base no período de 1956 a 1984. Pesq. Agropec. Gaúcha, 15:29-38, 2009.

MAZURANA, J.; CASSOL, E.A.; SANTOS, L.; ELTZ, F.L.F. \& BUENO, A.C. Erosividade, padrões hidrológicos e período de retorno das chuvas erosivas de Santa Rosa, RS. R. Bras. Eng. Agríc. Amb., 13:975-983, 2009.

NASCIMENTO, C.W.A. \& CHAVES, I.B. Erosividade e características da chuva correlacionadas com perdas de solo em Alagoinha - PB. Ci. Rural, 26:407-412, 1996.

OLIVEIRA, M.A.T. Processos erosivos e preservação de áreas de risco de erosão por voçorocas. In: GUERRA, A.J.T.; SILVA, A.S. \& BOTELHO, R.G.M., orgs. Erosão e conservação dos solos: Conceitos, temas e aplicações. Rio de Janeiro, Bertrand Brasil, 1999. p.57-99.

PEDROLLO, O.C. GEDAC: Gerenciamento de dados contínuos. Manual do usuário. Porto Alegre, IPH, 1997. $60 \mathrm{p}$.

PEÑALVA-BAZZANO, M.G.; ELTZ, F.L.F. \& CASSOL, E.A. Erosividade, coeficiente de chuva, padrões e período de retorno de chuvas de Quarai, RS. R. Bras. Ci. Solo, 31:12051217, 2007.

RUFINO, R.L.; BISCAIA, R.C.M. \& MERTEN, G.H. Determinação do potencial erosivo da chuva do Estado do Paraná, através de pluviometria: Terceira aproximação. R. Bras. Ci. Solo, 17:439-444, 1993.

SILVA, A.M.; SCHULZ, H.E. \& CAMARGO, P.B. Erosão e hidrossedimentologia em bacias hidrográficas. 2.ed. São Carlos, RiMa, 2007. 158p.

VAL, L.A.; BAHIA, V.G.; FREIRE, J.C. \& DIAS JUNIOR, M.S. Erosividade das chuvas em Lavras - MG. Ci. Prática, 10:199-209, 1986.

WILKS, D.S. Statistical methods in the atmospheric sciences. London, Elsevier, 2006. 630p.

WISCHMEIER, W.H. \& SMITH, D.D. Rainfall energy and its relationship to soil loss. Trans. Am. Geophys. Union, 39:285-91, 1958.

WISCHMEIER, W.H. \& SMITH, D.D. Predicting rainfall erosion losses: A guide to conservation planning. Wasington, USDA, 1978. 58p. (Agriculture Handbook, 537) 